\title{
Effect of hydrostatic pressure on the growth rates and encystment of flagellated protozoa isolated from a deep-sea hydrothermal vent and a deep shelf region
}

\author{
Michael S. Atkins ${ }^{1, *}$, O. Roger Anderson ${ }^{2}$, Carl O. Wirsen ${ }^{1}$ \\ ${ }^{1}$ Biology Department, Woods Hole Oceanographic Institution, Woods Hole, Massachusetts 02543, USA \\ ${ }^{2}$ Biological Oceanography, Lamont-Doherty Earth Observatory of Columbia University, Palisades, New York 10964, USA
}

\begin{abstract}
Six isolates of deep-sea flagellated protozoa were grown in culture at 1 to 300 atm to measure their growth response to increasing hydrostatic pressure. Three kinetoplastid flagellates and 1 choanoflagellate were isolated from deep-sea hydrothermal vent samples and 2 chrysomonads were isolated from deep continental shelf sediments. The growth rates of 2 species isolated from the vent, Caecitellus parvulus and Rhynchomonas nasuta, were compared to the growth rates of shallow-water strains of the same species. Deep-sea isolates of $C$. parvulus and $R$. nasuta had a higher rate of growth at higher pressures than did their shallow-water counterparts. This feature could result from adaptation to higher pressure upon sinking to depth or with time on the ocean bottom. Four of the 6 deep-sea isolates-C. parvulus, R. nasuta and the 2 chrysomonads-were capable of growth at pressures corresponding to their respective depths of collection, indicating that these species could be metabolically active at these depths. C. parvulus and $R$. nasuta encysted at pressures greater than their depth of collection. The choanoflagellate isolate was observed to encyst at pressures greater than 50 atm. These findings suggest a potential ecological role for encystment in deep-sea/water-column coupling. Cosmopolitan or epipelagic species, such as $C$. parvulus and $R$. nasuta, may be transported on sedimenting particles into the deep sea, where encystment at high pressure could serve as a mechanism for pelagic renewal by advection via hydrothermal plume entrainment and thermohaline circulation.
\end{abstract}

KEY WORDS: Protozoa - Flagellate Chyrysomonad - Hydrostatic pressure Growth rate Encystment · Hydrothermal vent Continental shelf. Extreme environment

\section{INTRODUCTION}

Flagellated protozoa are ubiquitous components of the complex microbial food webs found in every habitable environment on this planet. The presence and species richness of protozoan organisms has been documented throughout terrestrial and aquatic ecosystems worldwide. In shallow benthic and pelagic marine ecosystems the importance of protozoan associations in energy transfer through aquatic food webs has been well established (Azam et al. 1983, Alldredge et al. 1986, Patterson et al. 1993). High bacterial productivity coupled with consumption of bacterial biomass by heterotrophic flagellates has been suggested as one possible mechanism for the transfer of energy,

•E-mail: msatkins@mit.edu carbon and nutrients to higher trophic level organisms (Fuhrman \& Azam 1980, Azam \& Fuhrman 1984, Caron et al. 1985. Caron 1991a). Bacterivorous flagellates also have been found to be important nutrient remineralizers, capable of regenerating nutrients and other inorganic molecules, enhancing the bioavailability of these compounds to other organisms (Fenchel 1982, Sherr et al. 1983, Caron \& Goldman 1990). These data have shown that flagellated protozoa of the neritic benthos and epipelagos are integral components of carbon and nutrient cycling within oceanic microbial food webs. However, the importance of microbial associations and particularly protozoan assemblages in deep-sea regions is not well known. This is due to the difficulty and expense of abtaining live samples from the deep sea. Yet with greater than $88 \%$ of earth's biosphere below $1000 \mathrm{~m}$ of seawater, the ecological significance 
of microbial decomposition and remineralization in the deep sea becomes apparent (Jannasch \& Wirsen 1984).

The present study was done to increase our knowledge of one aspect of flagellate activity in the deep sea; flagellate growth as affected by hydrostatic pressure. Attempts to culture natural populations of benthic and planktonic protozoa from the deep sea bring into question the effect of pressure as a selective mechanism, thereby preventing the isolation of pressure-adapted species. To address this and other ecologically relevant questions, the effect of hydrostatic pressure was measured on the growth rates of 4 flagellate species isolated from $2500 \mathrm{~m}$ at the $9^{\circ} \mathrm{N}$ hydrothermal vent site on the East Pacific Rise and 2 flagellates isolated from a $1500 \mathrm{~m}$ station on the continental shelf in the North Atlantic. These organisms were examined in pure culture at pressures ranging from 1 to 300 atm to determine the extent of barotolerance within each culture. The growth rates of 2 species isolated from the vent site, Caecitellus parvulus and Rhynchomonas nasuta, were compared to the growth rates of shallow-water strains of the same species.

\section{MATERIALS AND METHODS}

Sampling and enrichment. East Pacific Rise: Samples were collected from several sites at $2500 \mathrm{~m}$ depth within the $9^{\circ} \mathrm{N}$ hydrothermal vent site on the East Pacific Rise (EPR) using the DSV (Deep Submergence Vehicle) 'Alvin'. Samples were collected using 2 methods: (1) placement of substrates (e.g. rocks, mussels, tubeworms, glass-slides and settling blocks) into chambers on 'Alvin' for subsequent retrieval; and (2) suction-pump concentration of water samples into sterile sample jars.

North Atlantic: A box-core sediment sample was collected in July 1996 from a $1500 \mathrm{~m}$ station on the continental shelf in the North Atlantic Ocean.

All deep-sea samples were subjected to decompression during retrieval to the surface, where sub-samples were aliquoted into (1) enrichment media $(0.22 \mu \mathrm{m}$ filtered/autoclaved Vineyard Sound Water [VSW] and $0.01 \%$ sterile yeast extract); (2) formalin, at a final concentration of $3.7 \%$; and, (3) molecular grade ethyl alcohol (Quantum Laboratories), at a final concentration of $70 \%$.

Shallow-water samples: A sediment sample was collected in August 1996 from $2.5 \mathrm{~m}$ depth north of Pope's Island in New Bedford Harbor (NBH, MA, USA). A Chesapeake Bay isolate (CBR 1) was obtained from the culture collection of David Caron at the Woods Hole Oceanographic Institution.

Isolation and identification. Single cells were isolated from mixed populations in enriched cultures using the micromanipulation and dilution/extinction techniques outlined by Caron (1993) and by flow cytometry, in which individual cells were sorted using an Argon-ion laser (Becton-Dickinson FACStar plus Cell Sorter). Cell viability using flow cytometry was approximately 20 to $30 \%$

Once cells were isolated in pure culture they were identified to the genus or species level using light or transmission-electron microscopy. Microscopical observations were compared to the Biogeochemical Ocean Flux Study Protist Video Database (University of Bristol, UK) and to Patterson \& Larsen (1991). Table 1 lists the protists obtained from each of the experimental stations.

Hydrostatic pressure experiments. Prey preparation: Bacterial prey cultures (Halomonas halodurens) grown in $0.22 \mu \mathrm{m}$ filtered/autoclaved VSW and $0.01 \%$ sterile yeast extract were heat-killed to prevent overgrowth, washed free of yeast extract, secondary metabolites and growth inhibitors by repeated centrifugation and resuspension, and finally distributed into microfuge storage tubes and pelleted. Microfuge tubes, containing an equivalent quantity and quality of pelleted bacteria, were stored at $-70^{\circ} \mathrm{C}$ until used as a food source in the pressure experiments.

Experimental organism preparation: Each isolate was grown in sterile $50 \mathrm{ml}$ tissue culture flasks (Fisher Scientific) in growth media $(0.22 \mu \mathrm{m}$ filtered/autoclaved VSW and $10^{8}$ to $10^{9}$ heat-killed prey cells $\mathrm{ml}^{-1}$ ) prior to the start of each experiment to bring flagellate cells used for syringe inocula up to a density between $10^{5}$ to $10^{6} \mathrm{ml}^{-1}$.

Pressure vessel and syringe preparation: Seven OC-16 reactor pressure vessels (High Pressure Equipment Co., Inc.), previously described by Jannasch \& Wirsen (1984), were rinsed, filled with water and equilibrated at the experimental temperature. Sterile syringes (10 cc, Becton Dickinson) capped with rubber serum-stoppers were used as incubation tubes inside the pressure vessels.

Control experiments: To determine if the syringes inside the pressure vessels or the vessels themselves introduced artifacts, growth rates were measured using replicate syringes inside (internal) and outside (external) pressure vessels and compared with growth rates in culture flask controls (Fig 1). With the exception of the vent isolate BSZ 3 (Massisteria marina), growth rates of flagellates in syringes internal and external to pressure vessels were generally the same and closely approximated growth rates in culture flask controls. Organisms that failed to show similar growth rates among the controls, such as BSZ 3, were not used in these experiments. Note in Fig. 1 that, with the exception of Rhynchomonas nasuta strain BSZ 1, the absolute number of protists was higher in flask controls as the cultures approached stationary phase. This 
Table 1. Protozoa collected from deep-sea and shallow locations. Flagellates in bold print were used in these experiments. Positive identification was made for Rhynchomonas nasuta and Caecitellus parvulus; all others have tentative icientifications only. Temperature shown is the temperature at which these organisms currently are grown in laboratory culture

\begin{tabular}{|c|c|c|c|c|c|c|}
\hline Isolate & Collection location & Collection date & $\begin{array}{l}\text { Collection } \\
\text { depth (m) }\end{array}$ & $\begin{array}{l}\text { Positive } \\
\text { idcontification }\end{array}$ & $\begin{array}{l}\text { Tentative } \\
\text { Identification }\end{array}$ & $\mathrm{T}\left({ }^{\circ} \mathrm{C}\right)$ \\
\hline BRM 1 & $9^{\circ} \mathrm{N}$ Biovent Riftia and Mussel Bed & December 1995 & 2500 & & Bodo saliens & 20 \\
\hline BRM 2 & $9^{\circ} \mathrm{N}$ Biovent Riftia and Mussel Bed & December 1995 & 2500 & & Ancyromonas sp. & 3.5 \\
\hline BSZ 1 & $9^{\circ} \mathrm{N}$ Biovent Serpulid Zone & April 1995 & 2500 & Rhynchomonas nasuta & & 20 \\
\hline BSZ 2 & $9^{\circ} \mathrm{N}$ Biovent Serpulid Zone & December 1995 & 2500 & Rhynchomonas nasuta & & 20 \\
\hline BSZ 3 & $9^{\circ} \mathrm{N}$ Biovent Serpulid Zone & December 1995 & 2500 & & Massisteria manna & 20 \\
\hline $\mathrm{BSZ} 4$ & $g^{\circ} \mathrm{N}$ Biovent Serpulid Zone & December 1995 & 2500 & & Monosiga sp. & 20 \\
\hline BSZ 5 & $9^{\circ} \mathrm{N}$ Biovent Serpulid Zone & December 1995 & 2500 & & Monosiga sp. & 20 \\
\hline BSZ 6 & $9^{\circ} \mathrm{N}$ Biovent Serpulid Zone & December 1995 & 2500 & & Monosiga sp. & 20 \\
\hline BSZ 7 & $9^{\circ} \mathrm{N}$ Biovent Serpulid Zone & December 1995 & 2500 & Caecitellus parvulus & & 20 \\
\hline BSZ 8 & $9^{\circ} \mathrm{N}$ Biovent Serpulid Zone & December 1995 & 2500 & & Benthic foraminifera & 3.5 \\
\hline EWM 1 & $9^{\circ} \mathrm{N}$ East Wall Mussel Bed & December 1995 & 2500 & Caecitellus parvulus & & 20 \\
\hline DA 1 & Deep Atlantic Shelf & July 1996 & 1500 & & Scuticociliate & 3.5 \\
\hline DA 2 & Deep Atlantic Shelf & July 1996 & 1500 & & Chrysomonad & 3.5 \\
\hline DA 3 & Deep Atlantic Shelf & July 1996 & 1500 & & Chrysomonad & 3.5 \\
\hline DA 4 & Deep Atlantic Shelf & July 1996 & 1500 & & Chrysomonad & 3.5 \\
\hline CBR 1 & Chesapeake Bay, MD & $\mathrm{n} / \mathrm{a}$ & 0.5 & Rhynchomonas nasuta & & 20 \\
\hline NBH 4 & New Bedford Harbor, MA & August 1996 & 2.5 & Caecitellus parvulus & & 20 \\
\hline
\end{tabular}
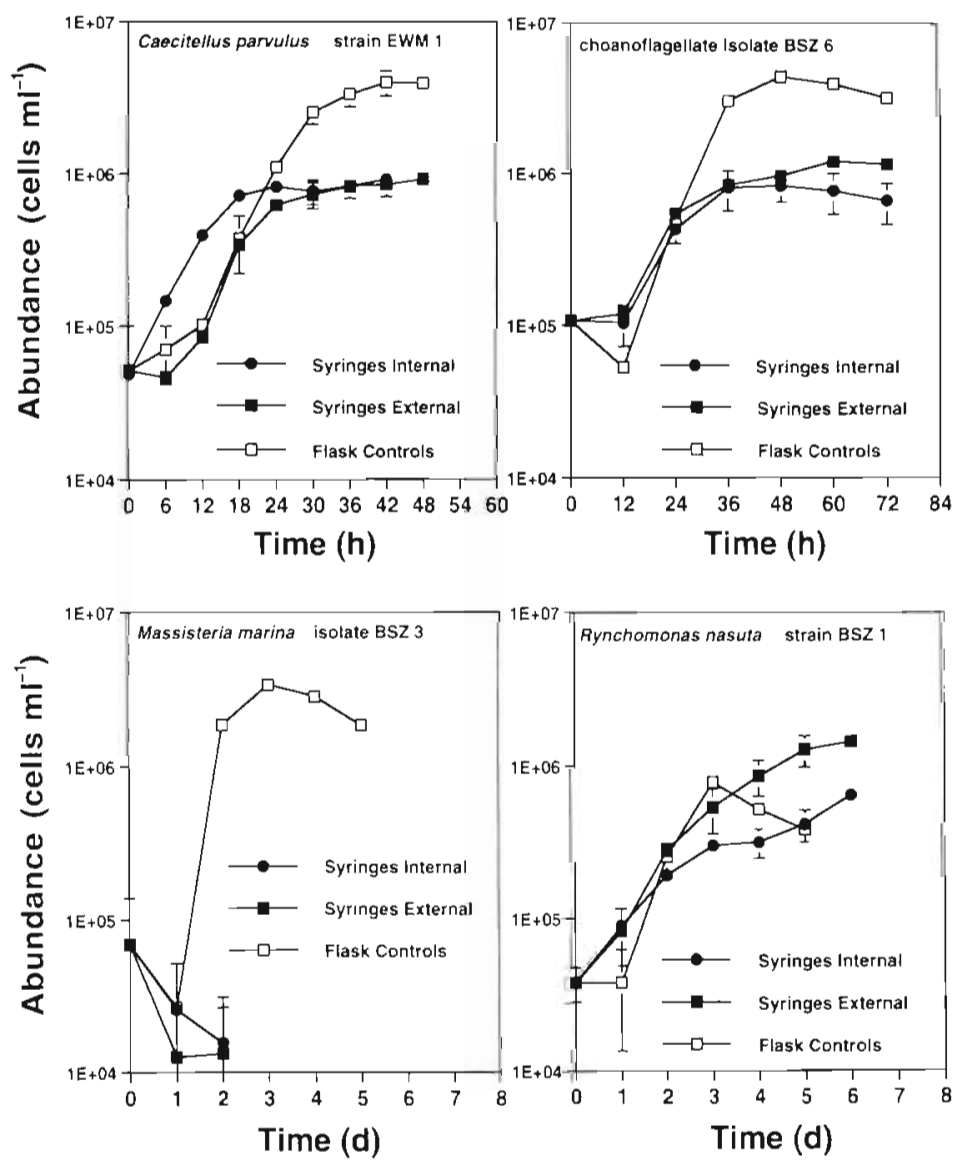

Fig. 1. Mean growth of several species of deep-sea flagellates in control experiments designed to test the feasibility of using pressure tubes (syringes) as culturing containers inside pressure vessels. Lines are bestfit lines drawn through mean abundance values $( \pm 1$ SD) plotted against time of sample collection result indicated the limitation through time of some essential growth requirement. Additional controls were done to determine if anoxic conditions developed in closed syringes over the time course of the pressure treatments (data not shown). Over the course of exponential phase, both Caecitellus parvulus and Rhynchomonas nasuta utilized only 50 to $60 \%$ of the available dissolved $\mathrm{O}_{2}$. Both cultures reached stationary phase at cell densities $>1 \times 10^{6}$ cells $\mathrm{ml}^{-1}$ with over $35 \%$ of the available dissolved $\mathrm{O}_{2}$ remaining. From these experiments, we concluded that anoxia does not occur in syringes over the time course of the pressure treatments (i.e. to the end of exponential growth). As all syringes and growth factors were replicated for each organism at each pressure, it was the effect of pressure which was considered to exert the most influence on growth rate differences.

Pressure experiments: To control for differences between syringes, aliquots were taken from single, well-mixed cultures containing $5 \times 10^{8}$ to $5 \times 10^{9}$ heat-killed bacterial cells $\mathrm{ml}^{-1}$ and approximately $5 \times 10^{3}$ flagellates $\mathrm{ml}^{-1}$. Ten milliliter aliquots from each culture were placed inside each of 7 syringes, labeled $1,50,100,150,200,250$ and $300 \mathrm{~atm}$ following the experimental design outlined below. Three replicate syringes for each organism were placed inside each of the 7 pressure vessels; the vessels were topped with water, then compressed to the experimental pressure. Two 
strains of the same species (6 syringes per vessel) simultaneously could be measured at each of the 7 pressures. Each experiment was performed 3 times.

Sampling. Cell counts were done using both multiple time points and end points. In time-point sampling, pressure vessels were slowly decompressed to atmospheric pressure, opened and the syringes removed. Each syringe was inverted, the serum-stopper cap removed and the plunger withdrawn about $0.5 \mathrm{cc}$ to introduce a small air bubble into the syringe chamber. The serum stopper was replaced and the syringe was inverted several times using the air bubble to detach and mix flagellates. The air bubble was removed and approximately $200 \mu \mathrm{l}$ was transferred into a sterile microfuge tube. The syringes were recapped, replaced into the vessels and recompressed within 10 to $15 \mathrm{~min}$ after decompression. In end point sampling, samples were taken only once, at the end of exponential growth, the timing of which had previously been determined during time-point sampling. End-point sampling eliminated the effects of decompression, which may have affected growth rate results.

Because time-point sampling introduced several decompression/recompression events into an experiment in which relative growth rates are a function of constant pressure, control experiments were done to determine whether end-point sampling and time-point sampling yielded similar results. Fig. 2 shows data from an experiment with Caecitellus parvulus strain EWM 1 which compares end-point and time-point sampling under conditions of variable hydrostatic pressure at $20^{\circ} \mathrm{C}$. This figure shows that both sampling methods yield similar mean growth rates at pressures

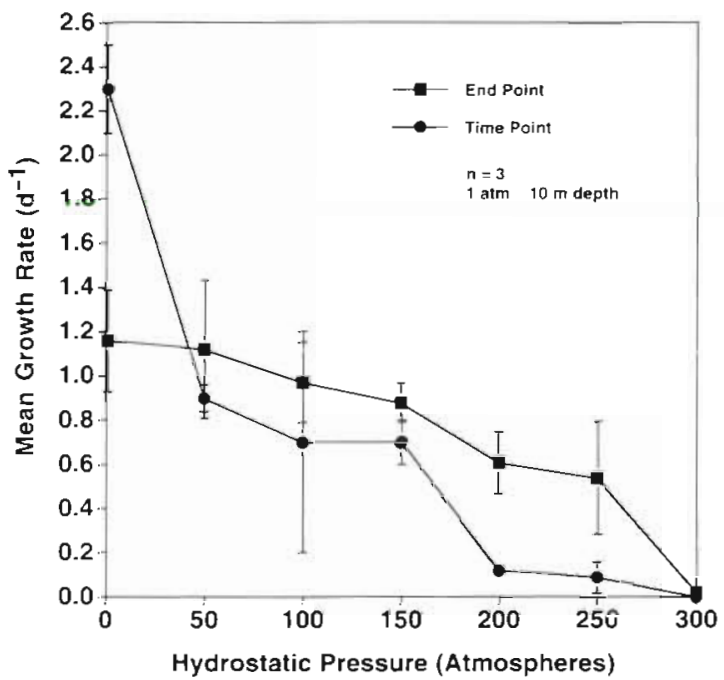

Fig. 2. Mean growth rates of Caecitellus parvulus strain EWM 1 measured by end-point and time-point sampling methods at different hydrostatic pressures. Lines are best-fit lines drawn through mean growth rate values $( \pm 1$ SD) plotted against hydrostatic pressure values at which growth was measured greater than 1 atm. The general trend between end points and time points remains approximately the same, which is a decrease in growth rate with increasing pressure. Because end-point sampling does not require a decompression/recompression event during the course of an experiment, it was used instead of time-point sampling in these experiments. This does not apply to experiments at atmospheric pressure, which were still done using multiple time points. Endpoint sampling did require, however, that measurements be made close to the beginning and termination of exponential growth and accurate end points were determined using time-point sampling curves.

Cell counts and growth rate calculations. From the microfuge tube, exactly $90 \mu \mathrm{l}$ was aliquoted into a labeled borosilicate glass tube containing $10 \mu \mathrm{l}$ of Acid Lugol's Solution $(1 \mathrm{~g}$ iodine [I] $+2 \mathrm{~g}$ potassium iodide [KI] dissolved in $200 \mathrm{ml} \mathrm{MQ} \mathrm{H}_{2} \mathrm{O}$; add $20 \mathrm{ml}$ glacial acetic acid). The remaining $110 \mu \mathrm{l}$ was observed directly on a Palmer-Maloney depression slide using phase contrast light microscopy at $400 \times$ magnification. In this way, the physical condition and general abundance of the cells was assessed just prior to counting. Cells were counted 2 times on the center grid of a hemocytometer unless culture densities were low, in which case 2 whole-grid ( $9 \times$ center) counts were made and averaged. These data were used to calculate mean relative growth rates at variable hydrostatic pressure and constant temperature. In time-point sampling, the per capita growth rate was determined from a linear regression of a plot of the natural logarithm of cell abundance through time. Growth rates were determined during logarithmic growth only, prior to the potential limitation by any growth factor or anoxia. In end-point sampling, the per capita growth rate was calculated using the following equation:

$$
\ln N_{l} / N_{0} \times 1 / t
$$

where $N_{t}$ is the number of flagellates in the culture at time $t$, the end point, and $N_{0}$ is the initial number of flagellates in the culture.

Transmission electron microscopy (TEM). Samples collected from high pressure treatments were gently sedimented by centrifugation and fixed for $20 \mathrm{~min}$ at $5^{\circ} \mathrm{C}$ in $2 \%$ electron microscopic grade glutaraldehyde (Ladd Res. Industries, VT, USA) prepared in $0.05 \mathrm{M}$ cacodylate buffer $(\mathrm{pH}=7.8)$. Particle preparations were washed, deposited on carbon-coated, formvarcovered grids, air dried and negatively stained with $2 \%$ potassium phosphotungstate solution $(\mathrm{pH}=6.5)$ or shadowed with a carbon platinum source. Preparations for TEM used standard methods for fixation and embedding (e.g. Anderson 1992) and were observed with a Philips 201 transmission microscope operated at $60 \mathrm{kV}$. 
Experimental design and statistical analyses. The following experiments were manipulated to fit a split split-plot design in which the measured mean relative growth rate of 2 strains simultaneously could be tested for pressure dependence and time invariance (see Snedecor \& Cochran 1982, p. 328, example 16.15.1, for a more comprehensive description of this design). Each experiment was conducted at 7 different pressures, from $1 \mathrm{~atm}$ to $300 \mathrm{~atm}$ in $50 \mathrm{~atm}$ increments $(1,50,100,150,200,250,300 \mathrm{~atm})$, and was repeated 3 different times, $T_{1}, T_{2}$ and $T_{3}$ for each organism.

\section{RESULTS}

Isolation procedures yielded 11 isolates from the $9^{\circ} \mathrm{N}$ hydrothermal vent sites and 4 isolates from the continental shelf region in the North Atlantic (Table 1). Two vent isolates, BRM 2 and BSZ 8, and all continental shelf isolates are psychrophilic, with growth optima near $3.5^{\circ} \mathrm{C}$. All other vent isolates and the 2 shallowwater strains grow well at $20^{\circ} \mathrm{C}$. Several isolates were identified as different strains of 2 species in 2 different genera, which were positively identified by D. J. Patterson using NTSC video recordings (authors' pers. com.) as Caecitellus parvulus (strains BSZ 7, EWM 1 and NBH 4) and Rhynchomonas nasuta (strains CBR 1, BSZ 1 and BSZ 2). Patterson et al. (1993) point out that Griessmann (1913) previously assigned Caecitellus parvulus to the genus Bodo, but ultrastructural analysis revealed (1) mitochondria with tubular christae; (2) lack of paraxial rods; (3) a mouth supported by a horseshoe-shaped arc of microtubules; (4) that the microtubules are associated with massive electrondense material and (5) that there is no kinetoplast. They concluded that these observations contradict assignment to the genus Bodo. Although Caecitellus is a genus of uncertain taxonomic affinity, it is used throughout this paper with regard to the species parvulus. Isolates with tentative species and/or genera assignments include BRM 1 (Bodo saliens), BRM 2 (Ancyromonas sp.), BSZ 3 (Massisteria marina) and BSZ 4, 5 and 6 (Monosiga sp.). None of the continental shelf isolates have been positively identified.

Growth rates and encystment at high pressure. The growth rates of Caecitellus parrulus strains EWM 1 (vent isolate) and $\mathrm{NBH} 4$ (shallow-water isolate) were measured and compared under conditions of variable hydrostatic pressure (Fig. 3). Both strains had a decreasing growth rate with increasing pressure, but the vent strain had a higher rate of growth at all pressures relative to the shallow-water strain ( $p \leq 0.01)$. Both strains exhibited barotolerance to increasing pressure. Within 2 to $4 \mathrm{~d}$ of compression to pressures greater than 250 atm, both strains began to encyst. After $5 \mathrm{~d}$ at

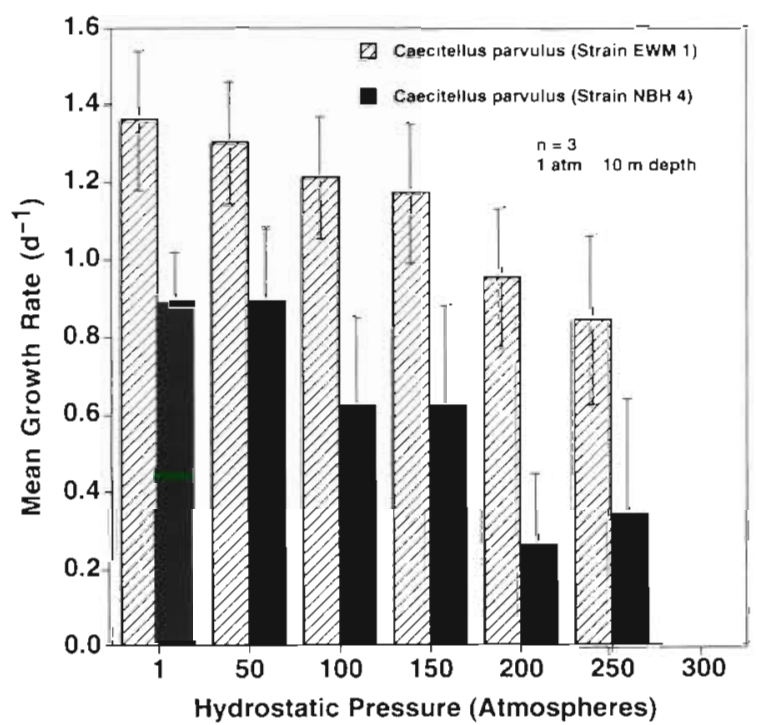

Fig. 3. Mean growth rates of Caecitellus parvulus strain EWM 1 from $2500 \mathrm{~m}$ and strain NBH 4 from a shallow-water location with increasing hydrostatic pressure. (Error bars are $\pm 1 \mathrm{SD}$ )

300 atm, for example, all cells observed and counted were encysted forms. All encysted cultures of compressed Caecitellus parvulus gave rise to dense cultures of swimming and feeding trophs within 3 to $5 \mathrm{~d}$ of decompression to atmospheric pressure and transfer to new media (data not shown).

Similar results were obtained with Rhynchomonas nasuta strains BSZ 1 (vent isolate) and CBR 1 (shallowwater isolate) (Fig. 4). Both strains exhibited a decreasing growth rate with increasing pressure, but the vent strain had a higher rate of growth at higher pres-

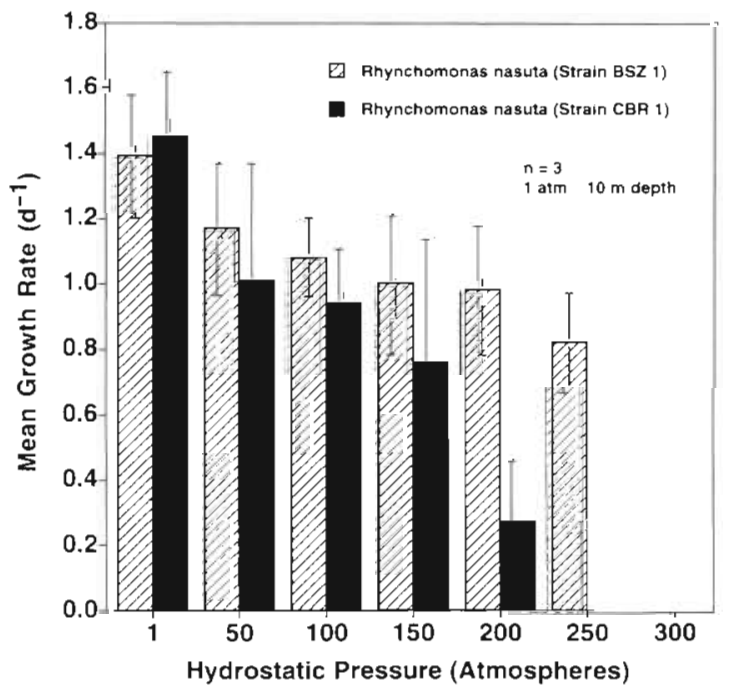

Fig. 4. Mean growth rates of Rhynchomonas nasuta strain BSZ 1 from $2500 \mathrm{~m}$ and strain CBR 1 from a shallow-water location with increasing hydrostatic pressure. (Error bars are $\pm 1 \mathrm{SD}$ ) 
sures relative to the shallow-water strain $(p \leq 0.05)$. Both strains exhibited barotolerance toward increasing pressure. However, only the vent strain grew at $250 \mathrm{~atm}$ - the pressure at its collection depth. Both strains of $R$. nasuta began to form cysts within 2 to $4 \mathrm{~d}$ of compression to pressures greater than 250 atm and these cysts also gave rise to dense cultures of swimming, feeding trophs upon release from the inhibitory pressure.

The choanoflagellate vent isolate, BSZ 6, showed little barotolerance (Fig. 5). It did not grow at pressures greater than or equal to $100 \mathrm{~atm}$. At $100 \mathrm{~atm}$ and higher, all cells encysted. These cysts gave rise to dense cultures of swimming choanoflagellates within 3 to $5 \mathrm{~d}$ of decompression to atmospheric pressure. The psychrophilic vent isolate, BRM 2, showed high barotolerance to - and possibly a growth optimum at150 atm. It did not grow or encyst at pressures higher than 150 atm (Fig. 5).

Fig. 6 compares 2 psychrophilic continental shelf isolates, DA 2 and DA 3 . The growth rate of isolate DA 2 decreased with increasing pressure. While it grew at pressures up to $200 \mathrm{~atm}$, encystment was not observed at any pressure. Isolate DA 3 grew best at $50 \mathrm{~atm}$ and was barotolerant to $150 \mathrm{~atm}$. No growth was observed at pressures greater than $150 \mathrm{~atm}$, and encystment did not occur at any pressure.

Light and electron microscopic observations. The process of cell encystment induced by hydrostatic pressure was investigated using light microscopy and TEM (Figs. 7 \& 8). Fig. 7 shows Caecitellus parvulus strain EWM 1 trophs in culture at atmospheric pressure (Fig. 7A) and at 300 atm after $2 \mathrm{~d}$ (Fig. 7B) and $5 \mathrm{~d}$

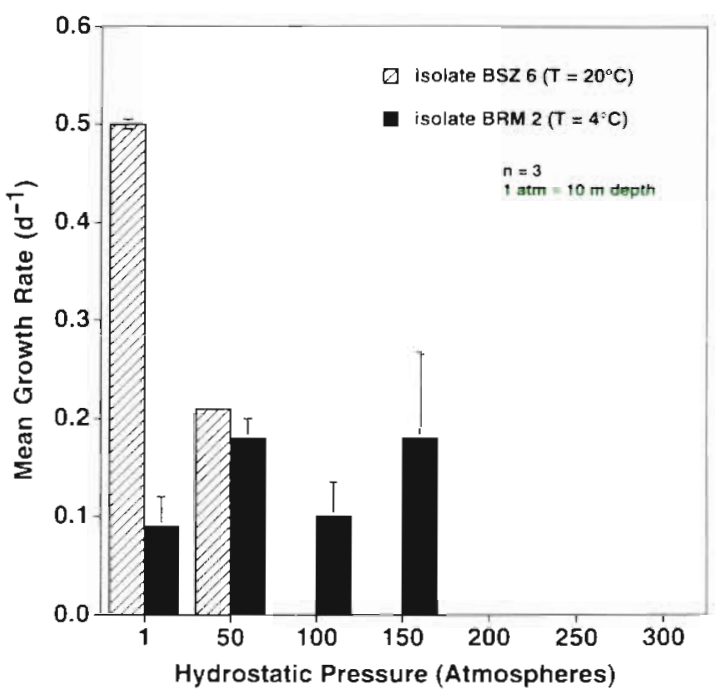

Fig. 5. Mean growth rates of a choanoflagellate 1 solate, BSZ 6 , and the psychrophilic isolate BRM 2 with increasing hydrostatic pressure. These organisms were collected at $2500 \mathrm{~m}$. (Error bars are $\pm 1 \mathrm{SD}$ )

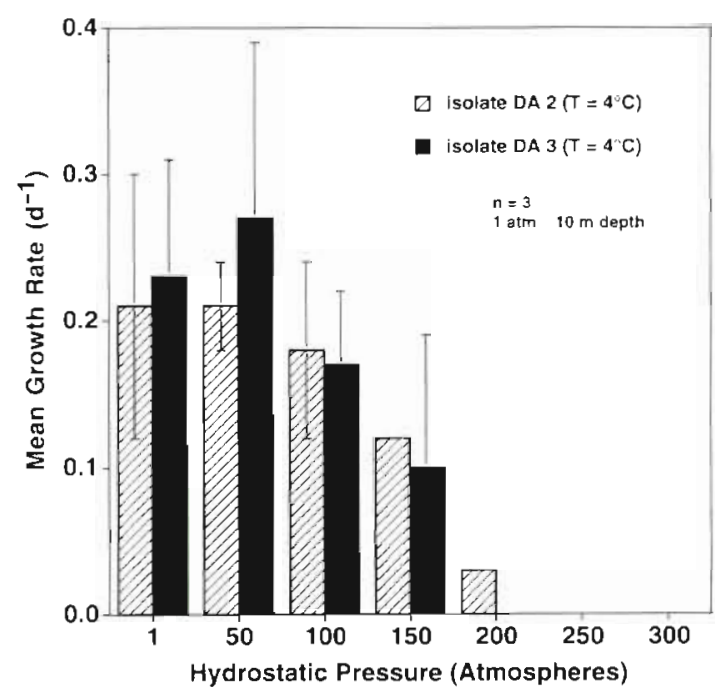

Fig. 6. Mean growth rates of the psychrophilic isolates DA 2 and 3 with increasing hydrostatic pressure. These organisms were collected at $1500 \mathrm{~m}$. (Error bars are $\pm 1 \mathrm{SD}$ )

(Fig. 7C) exhibiting gradual thickening of the cell wall, increased opacity of the cytoplasm and resorption of the flagellum. Similar results were observed in Rhynchomonas nasuta cultures. Fig. 7D shows $R$. nasuta strain BSZ 1 trophs in culture at atmospheric pressure. Cultures collected from high pressure treatment after $4 \mathrm{~d}$, and immediately fixed for electron microscopy, contained flagellated and encysted cells (Fig $7 \mathrm{E}-\mathrm{I}$ ). The long flagellum ( 5 to $7 \mu \mathrm{m}$ ), thickened in the middle portion, has fine trailing filaments approximately $30 \mathrm{~nm}$ thick (Fig. 7E). The tip was slightly swollen (Fig. 7E, F). Spherical cysts (Fig. $7 \mathrm{H}$ ) observed in the same preparation were approximately $6 \mu \mathrm{m}$, although larger ones (up to $10 \mu \mathrm{m}$ ) were also present. Higher magnification, negative-stained preparations (Fig. 7I) show that the cyst wall is smooth and lacks ornamentation.

Ultrathin sections of the choanoflagellate isolate BSZ 6, grown in cultures at ambient atmospheric pressure (Fig 8A), contained a prominent nucleus, mitochondria with flattened cristae and a lightly granular matrix, osmiophilic reserve bodies, and digestive vacuoles with ingested bacteria. Portions of the fringe of microvilli were observed in longitudinal sections. Cells collected from high pressure treatments after $4 \mathrm{~d}$ showed varying stages of encystment (Fig 8B-D). Some cells appeared nearly normal (Fig 8B) and contained microvilli in some sections, although the mitochondria were consistently enlarged in the pressuretreated cells. As the cells encysted, no microvilli were observed, the nucleus became increasingly smaller and irregular in shape, reserve bodies were fewer, remaining digestive vacuoles contained only late stages of digested matter, and the cell was gradually enclosed in a thickened wall that at first was thin and 

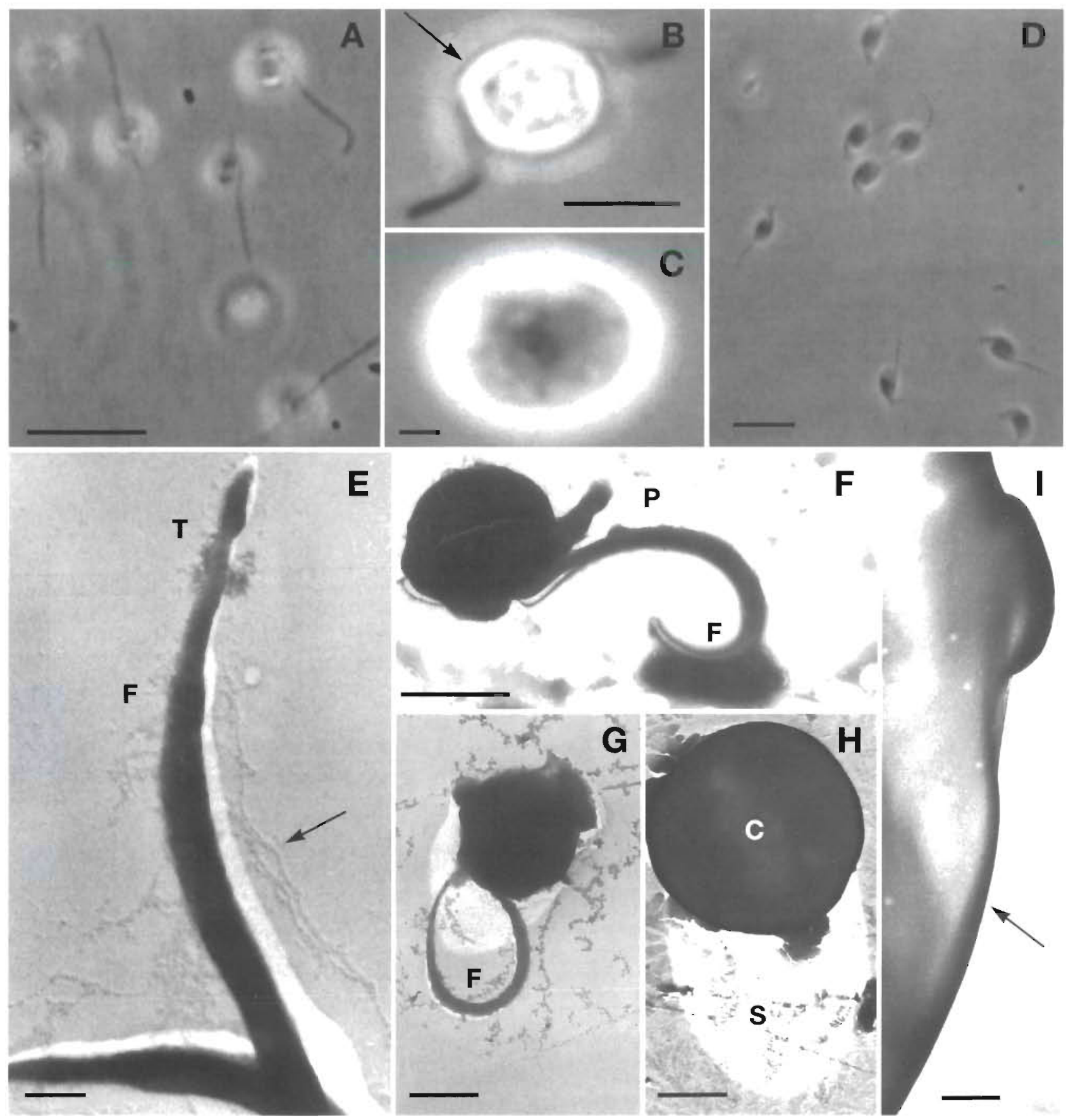

Fig. 7. Light microscopic images of Caecitellus parvulus strain EWM 1 (A-C) and Rhynchomonas nasuta strain BSZ 1 (D), and transmission electron microscopic images of $R$. nasuta motile cells (E-G) and cysts $\left(H_{1}\right.$ I) in whole particle preparations. (A) $C$. parvulus trophic cells cultured at atmospheric pressure showing normal apical and trailing flagella. (B) A cell after $2 \mathrm{~d}$ at 300 atm showing early stages of cyst wall formation (arrow) and resorption of flagella. Note increase in cell size. (C) A fully encysted cell after $5 \mathrm{~d}$ at $300 \mathrm{~atm}$. (D) $R$. nasuta trophic cells cultured at atmospheric pressure showing typical proboscis and trailing flagellum. (E) A carbon-platinum, shadowed flagellum (F) with trailing $30 \mathrm{~nm}$ thick filaments (arrow) and characteristic swollen tip ( $T$ ). (F) Negatively stained motile cell showing the proboscis (P) and curved flagellum (F) with a densely stained, rod-shaped bacterium near the tip. (G) Carbon-platinum, shadowed motile cell with curved flagellum (F). (H) Carbon-platinum, shadowed cyst (C), with a smooth surface, casting a typical shadow (S) for a spheroidal body. (I) An enlarged view of the edge of a cyst showing the smooth surface with a thin negatively stained outer layer (arow). Scale bars in (A), (B), and (D) $=5 \mu m ;(C)=2 \mu m ;(E)$ and $(\mathrm{I})=0.3 \mu \mathrm{m} ;$ and $(\mathrm{F}-\mathrm{H})=2 \mu \mathrm{m}$ 


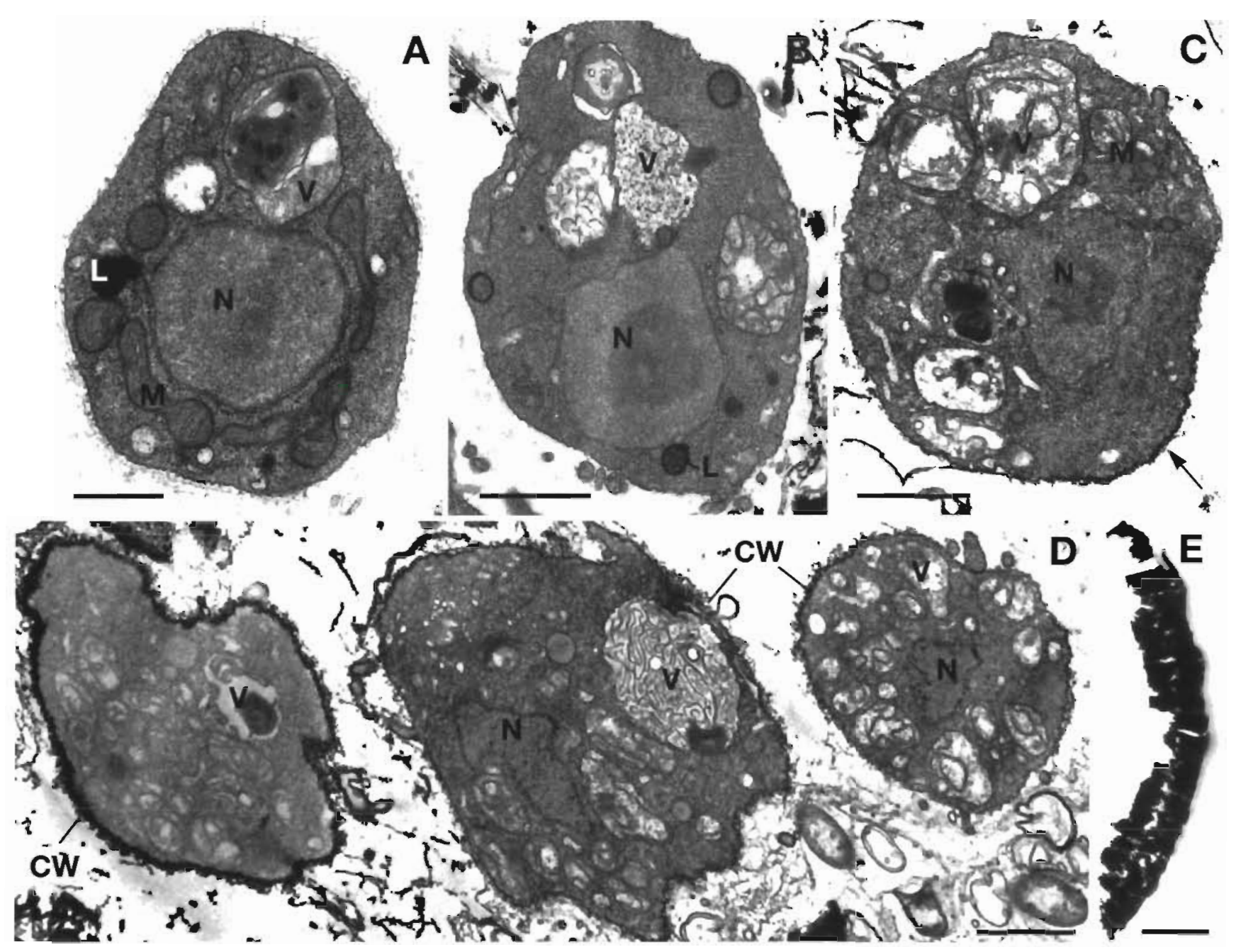

Fig. 8. Ultrathin sections of choanoflagellates cultured at ambient atmospheric pressure (A) and at 300 atm (B-E). (A) Normal cell with prominent nucleus $(N)$; mitochondria with flattened cristae and lightly granular matrix $(M)$; osmiophilic, reserve bodies that appear to be lipid (L), and digestive vacuoles ( $V$ ) containing early stages of digested food. (B) Pressure-treated cell with almost normal appearance compared to (A) showing, however, a somewhat more irregularly shaped nucleus (N), some reserve bodies (L), and digestive vacuoles (V) mainly in late stages. (C) A cell showing more advanced evidence of encystment (note light deposit of granular material on the cell surface, arrow) with irregularly shaped nucleus (N), enlarged digestive vacuoles with loosely arranged membranous components and few dense reserve bodies. (D) A series of cells showing signs of increasing encystment (right to left). The nucleus $(\mathrm{N})$ is smaller and more irregular in shape. Digestive vacuoles (V), when present, are in late stages with only membranous matter; the surface of the cell is increasingly enclosed by an electron-dense granular deposit that appears to be an early stage of cyst wall deposition (CW). (E) An electron-opaque section of a wall, apparently a fully formed cyst, exhibiting a brittle quality and smooth outer surface as is also characternstic of kınetoplastid cysts as in Fig. 7I. Scale bars in (A) and (E) $=$ $0.5 \mu \mathrm{m}$, others $=1 \mu \mathrm{m}$

granular (Fig. 8C, D). Subsequent stages showed. a more complete coating of the granular material and the cytoplasm stained less densely, perhaps due to reduced penetration through the developing wall (Fig. 8D, left). In the most advanced stages, a thick, electron-dense wall (ca 0.3 to $0.7 \mu \mathrm{m}$ ) was formed (Fig. 8E). It was impervious to the resin. Hence, we could not observe the state of the cytoplasm in the fully encysted cells. These fine structural data support light microscopic observations that high pressure treatment gradually induces encystment. Flagellated stages of Rhynchomonas nasuta persist for some time up to several days during onset of pressure treatments, but the choanoflagellates appear to be more susceptible to pressure-induced encystment based on light and electron microscopic evidence.

Encystment was only observed in hydrothermal vent isolates cultured at $20^{\circ} \mathrm{C}$. Live observation of Caecitellus parvulus strains after $8 \mathrm{~d}$ at 250 atm revealed a very low abundance of mostly swimming cells; very few 


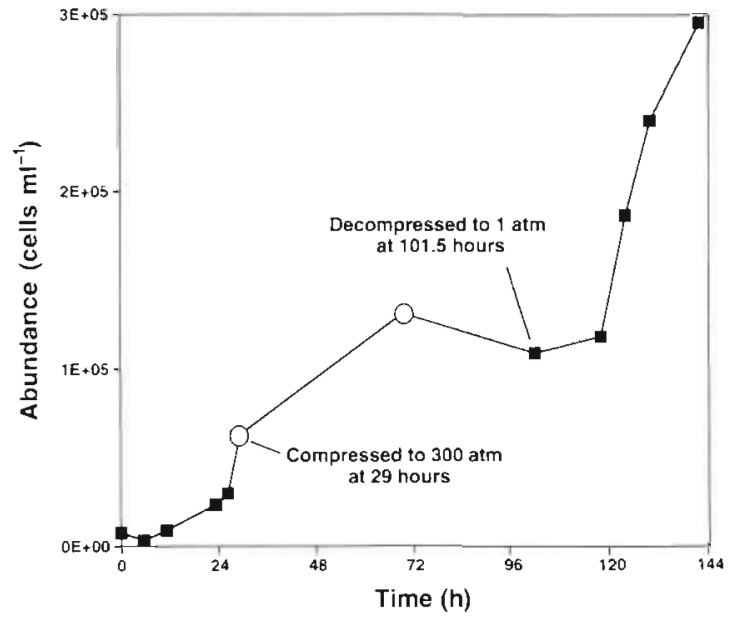

Fig. 9. Mean growth of Caecitellus parvulus strain EWM 1 in an experiment to determine the effect of compression and decompression events on growth rate. Growth was initiated at atmospheric pressure (1) for $29 \mathrm{~h}$. Cultures then were compressed to $300 \mathrm{~atm}$ for $72.5 \mathrm{~h}(0)$ and released from pressure at $101.5 \mathrm{~h}(\mathbf{\square})$

cells had encysted. But after only 2 d at 300 atm, most cells had encysted or were in the process of encysting (Fig. 7B). After 5 d at 300 atm, all cells were encysted (Fig. 7C). When decompressed to atmospheric pressure and transferred to new media, all encysted cultures grew to a density of approximately $1 \times 10^{6}$ trophs per ml within $5 \mathrm{~d}$.

To determine if this organism resumes its growth rate upon release from an inhibitory pressure, pressure was varied over the course of an experiment (Fig. 9). Replicate cultures of Caecitellus parvulus strain EWM 1 initially were grown at 1 atm then compressed to $300 \mathrm{~atm}$ after $29 \mathrm{~h}$. Growth proceeded at a decreasing rate for an additional $40 \mathrm{~h}$ at $300 \mathrm{~atm}$ then began to decline for $32.5 \mathrm{~h}$ until the culture was decompressed to $1 \mathrm{~atm}$ at $101.5 \mathrm{~h}$. After a brief lag period, the growth rate increased to approximate that of the 1 atm exponential phase prior to the compression event.

\section{DISCUSSION}

The specific questions this work proposed to answer were: (1) what are the relative growth rates of deepsea protozoa cultured under conditions of varying hydrostatic pressure; and (2) are species retrieved and cultured by the experimental methods barophilicthat is, do they have an optimal pressure for growth that is higher than atmospheric pressure, or do they simply exhibit levels of barotolerance to extreme deepsea pressures? The observation of pressure-induced cell encystment in species of flagellates isolated from the $2500 \mathrm{~m}$ hydrothermal vent was unanticipated, as the pressures used in these experiments were not exceptionally high when compared with similar studies involving protozoan trophs retrieved from stations at greater depths and pressures (Burnett 1977, Small \& Gross 1985, Grassle 1986, Turley et al. 1988, Turley \& Carstens 1991, Turley 1993). However, the discovery that pressure-induced cysts yield active trophs upon release from an inhibitory pressure has ecological implications regarding flagellate seeding if advection to shallow waters can occur.

Oxygen consumption experiments confirmed that anoxia does not develop in syringes over the time course of the pressure treatments. In addition, encystment was not observed at any time in Caecitellus parvulus and Rhynchomonas nasuta controls grown at atmospheric pressure (data not shown). Since encystment occurred faster and more completely in replicate cultures at higher pressures than at lower pressures, and since all syringes and growth factors were replicated, it was the effect of pressure that contributed the most to growth rate differences between pressure treatments.

However, it must be cautioned that the growth rates reported here are relative growth rates given the experimental conditions, and should not be considered as the absolute growth rates of these organisms in the deep sea: the demonstration of relative growth rates under controlled conditions in the laboratory does not imply that these growth rates occur in nature

Four of 6 deep-sea isolates ( 2 vent; 2 shelf) exhibited growth at pressures corresponding to their depth of collection. These species, Caecitellus parvulus strain EWM 1 (Fig. 3), Rhynchomonas nasuta strain BSZ 1 (Fig. 4), and continental shelf isolates DA 2 and DA 3 (Fig. 6), potentially could be metabolically active at their respective depths of collection. The choanoflagellate isolate BSZ 6 is probably not active at its depth of collection, but may only exist there in an encysted state. Curiously, isolate BRM 2 and the other psychrophilic flagellates, DA 2 \& DA 3, did not grow well at pressures greater than $150 \mathrm{~atm}$ and, perhaps more importantly, they did not encyst at any pressure, including pressures inhibitory to growth. By comparison, Wirsen \& Jannasch (1975) also noted a decrease in metabolic activity at elevated pressures and cold temperatures, principally in biosynthesis more than respiration, for marine psychrophilic bacteria isolated from depths between 450 and $2500 \mathrm{~m}$.

Shallow-water strains of Caecitellus parvulus and Rhynchomonas nasuta exhibited growth up to or near the maximum pressures observed in deep-sea strains, and encystment occurred approximately at the same inhibitory pressure for both deep and shallow-water strains. However, it is interesting to note that deep-sea isolates had a higher rate of growth at higher pressures 
than did their shallow-water counterparts. This feature could result from some kind of genetic adaptation to higher pressure upon sinking to depth or with time on the ocean bottom. The difference currently is being investigated at the molecular level using DNA sequencing and denaturing-gradient gel electrophoresis (DGGE) analyses to determine if base-pair changes exist between the strains which could account for the observed difference in their response to growth under pressure. Alternatively, it has been suggested that variable responses to increasing pressure by different strains of a single species may result from differential expression of certain genes. Gene expression could show marked differences while DNA sequences could be identical in both shallow and deep-sea strains of the same species.

Experimental evidence of cell encystment at high pressure was confirmed both by light microscopy and TEM analysis (Figs. 7 \& 8). Among the initial responses to cyst formation appears to be resorption of the flagella and the development of a cyst wall, as shown in Fig. 7B, C. Brown \& Rogers (1978) showed that pressure-induced flagellar resorption occurred in the quadriflagellate Polytomella agilis compressed to $\sim 500 \mathrm{~atm}$. At this pressure, they found that the flagellar axoneme is internalized and disassembled in the cytoplasm into precursor subunits, including tubulin proteins, which are reutilized in regenerating new flagella when the organism is returned to atmospheric pressure after a 30 min exposure. The flagellar membrane also was internalized and was assumed to have been incorporated into the plasma membrane (Brown \& Rogers 1978). Loss of flagella may result in a decrease or absence of feeding in flagellates, and could be a stimulus for the early inducement of cyst formation. Evidence for this is found in the appearance only of late stages of digestive vacuoles accompanying early encystment in pressurized choanoflagellates (isolate BSZ 6) that eventually diminish during later stages of encystment (Fig. 8).

The cell wall gradually becomes thickened with a dense, granular material (Figs. $7 \mathrm{~B}, \mathrm{C}, \mathrm{I} \& 8 \mathrm{C}-\mathrm{E}$ ) that makes the cell relatively impermeable to harsh external conditions, as evidenced by the inability to fix and resinate fully encysted cells. The only evidence of fully encysted cells was a very thick, smooth cell wall with no cytoplasm or other internal structures (Fig. $8 \mathrm{E})$. The cellular source of the granular wall material is not known. There is no evidence of it in the Golgi apparatus and it appears to be secreted at the surface of the cell membrane. As mentioned above, the cytoplasm was not observed in fully encysted cells, but the sequence in Fig $8 \mathrm{~B}-\mathrm{D}$ shows a progression toward increasing electron dense granularity of the cytoplasm, a decrease in the number of digestive vac- uoles, and changes in the shape and size of the nucleus. Flagellar resorption, generation of a thick, smooth cell wall, and the development of a spheroidal cyst was typical among encysting flagellates used in these experiments.

The finding that all of the non-psychrophilic isolates encyst at pressures greater than those corresponding to their depths of collection suggests that some deepsea isolates may exist only as cysts at greater depths. These cells potentially could arrive in the deep sea from surface waters on sinking particulate matter (Silver \& Alldredge 1981, Silver et al. 1984, Patterson \& Fenchel 1990, Caron 1991b, Patterson et al. 1993, Bak et al. 1995). Fig. 9 illustrates that encystment resulting from increased pressure may not be permanent in Caecitellus parvulus. This experiment showed that while high pressure does inhibit C. parvulus growth, release from this inhibitory pressure allows growth to continue at the same initial rate. Decompression to a more favorable pressure induced rapid growth of active trophs in all cyst cultures formed at high pressure. Cosmopolitan or epipelagic species, such as C. parvulus and Rhynchomonas nasuta, may be transported on sedimenting particles into the deep sea, where encystment at high pressure could serve as a mechanism for pelagic renewal by advective or diffusive upwelling. Entrainment of cysts in advective hydrothermal plume water has the potential for delivering cysts more than $300 \mathrm{~m}$ above the vent field (Trivett 1991, Baker et al. 1994). Coupled with vertical flow along isopycnal lines and horizontal, especially upward, or diffuse flow across the thermocline (Gregg 1987), cysts can be carried to shallower waters on the order of days or weeks, where reduced pressure could favor the seeding of active trophs. These trophs could reattach to sedimenting detrital material, thereby reinitiating this benthic/pelagic cycle. It remains to be shown that cysts stay viable after long-term exposure to high pressure. These experiments currently are being conducted in laboratory incubators; however, in situ incubations of encysted cells should be conducted to assess the long-term responses of cysts and trophs in their natural setting.

Acknowledgements. We thank Drs Lauren Mullineaux, Stacy Kim, and Ewann Agenbroad-Berntson and the 'Alvin' crew for their assistance in collecting specimens from the $9^{\circ} \mathrm{N}$ hydrothermal vent; Glen Paradis at the MIT Cell Sorter Facility for helping isolate cells via flow cytometry; Dr David Patterson for assistance in flagellate identification; Dr Victoria Starczak for advice regarding the experimental design and statistical analyses and Dr David Caron for advice and the use of his laboratory and equipment. This work was supported by a National Science Foundation Graduate Research Fellowship. This is Woods Hole Oceanographic Institution contribution number 9715 and Lamont-Doherty Earth Observatory contribution number 5850 . 


\section{LITERATURE CITED}

Alldredge AL, Cole JJ, Caron DA (1.986) Production of heterotrophic bacteria inhabiting macroscopic organic aggregates (marine snow) from surface waters. Limnol Oceanogr 31:68-78

Anderson OR (1992) Cytochemical localization of acid phosphatase (Lysosomal and digestive enzyme activity). In: Lee JJ, Soldo AT (eds) Protocols in protozoology. Allen Press, Lawrence, $\mathrm{KS}, \mathrm{p} \mathrm{C} 22.1-\mathrm{C} 22.7$

Azam F, Fenchel T, Field JG, Gray JS, Meyer-Reil LA, Thingstad $F$ (1983) The ecological role of water-column microbes in the sea. Mar Ecol Prog Ser 10:257-263

Azam F, Fuhrman JA (1984) Measurement of bacterioplankton growth in the sea and its regulation by environmental conditions. In: Hobbie JE, Williams PJL (eds) Heterotrophic activity in the sea. Plenum Publishing Corp, New York, p 179-196

Bak RPM, van Duyl FC, Nieuwland G (1995) Organic sedimentation and macrofauna as forcing factors in marine benthic nanoflagellate communities. Microb Ecol 29(2): $173-182$

Baker ET, Feely RA, Mottl MJ, Sansone FT, Wheat CG, Resing JA, Lupton JE (1994) Hydrothermal plumes along the East Pacific Rise, $8^{\circ} 40^{\prime}$ to $11^{\circ} 50^{\prime} \mathrm{N}$ : plume distribution and relationship to the apparent magmatic budget. Earth Planet Sci Lett 128:1-17

Brown DL, Rogers KA (1978) Hydrostatic pressure-induced internalization of flagellar axonemes, disassembly, and reutilization during flagellar regeneration in Polytomella. Exp Cell Res 117:313-324

Burnett BR (1977) Quantitative sampling of microbiota of the deep-sea benthos-1. Sampling techniques and some data from the abyssal central North Pacific. Deep Sea Res 24: $781-789$

Caron DA (1991a) Evolving role of protozoa in aquatic nutrient cycles. In: Reid PC, Turley CM, Burkill PH (eds) Protozoa and their role in marine processes. Springer-Verlag. Berlin, p 387-415

Caron DA (1991b) Heterotrophic flagellates associated with sedimenting detritus. In: Patterson DJ, Larsen J (eds) The biology of free-living heterotrophic flagellates. Clarendon Press, Oxford, p 77-92

Caron DA (1993) Enrichment, isolation, and culture of free-living heterotrophic flagellates. In: Kemp PF, Sherr BF, Sherr $E B$, Cole JJ (eds) Handbook of methods in aquatic microbial ecology. Lewis Publishers, Boca Raton, LA, p 77-89

Caron DA, Goldman JC (1990) Protozoan nutrient regeneration. In: Capriulo GM (ed) Ecology of marine protozoa. Oxford University Press, New York, p 283-306

Caron DA, Goldman JC. Andersen OK, Dennett MR (1985) Nutrient cycling in a microflagellate food chain. II. Population dynamics and carbon cycling. Mar Ecol Prog Ser $24: 243-254$

Fenchel T (1982) Ecology of heterotrophic microflagellates.

Editorial responsibility: Otto Kinne (Editor),

Oldendorf/Luhe, Germany
II. Bioenergetics and growth. Mar Ecol Prog Ser 8:225-231

Fuhrman JA, Azam F (1980) Bactenoplankton secondary production estimates for coastal waters of British Columbia, Antarctica, and California. Appl Environ Microbiol 39 $1085-1095$

Grassle JF (1986) The ecology of deep-sea hydrothermal vent communities. In: Blaxter JHS, Southward AJ (eds) Ad vances in marine biology. Academic Press, New York p 302-362

Gregg MC (1987) Diapycnal mixing in the thermocline J Geophys Res 92(C5):5249-5286

Griessmann K (1913) Über marine Flagellaten. Arch Protistenkd 32((1914)):1-78

Jannasch HW, Wirsen CO (1984) Variability of pressure adaptation in deep sea bacteria. Arch Microbiol 139:281-288

Patterson DJ, Fenchel T (1990) Massisteria marina Larsen \& Patterson 1990, a widespread and abundant bacterivorous protist associated with marine detritus. Mar Ecol Prog Ser 62:11-19

Patterson DJ, Larsen J (eds) (1991) The biology of free-living heterotrophic flagellates. Clarendon Press, Oxford

Patterson DJ, Nygaard K, Steinberg G, Turley CM (1993) Heterotrophic flagellates and other protists associated with oceanic detritus throughout the water column in the mid North Atlantic. J Mar Biol Assoc UK 73:67-95

Sherr BF, Sherr EB, Berman T (1983) Grazing, growth, and ammonium excretion rates of a heterotrophic microflagellate fed four species of bacteria. Appl Environ Microbiol 45:1196-1201

Silver MW, Alldredge A.L (1981) Bathypelagic marine snow: deep-sea algal and detrital community. J Mar Res 39(3): $501-530$

Silver MW, Gowing MM, Brownlee DC, Corliss JO (1984) Ciliated protozoa associated with oceanic sinking detritus. Nature 309:246-248

Small EB, Gross ME (1985) Preliminary observations of protistan organisms, especially ciliates, from the $21^{\circ} \mathrm{N}$ hydrothermal vent site. Bull Biol Soc Wash 6:401-410

Snedecor GW, Cochran WG (1982) Statistical methods. The lowa State University Press, Ames, IA

Trivett DA (1991) Diffuse flow from hydrothermal vents. PhD thesis, Massachusetts Institute of Technology/Woods Hole Oceanographic Institution, Woods Hole, MA

Turley CM (1993) Maintenance of abyssal benthic foraminifera under high pressure and low temperature: some preliminary results. Deep Sea Res 40(4):643-652

Turley CM, Carstens M (1991) Pressure tolerance of oceanic flagellates: implications for remineralization of organic matter. Deep Sea Res 38(4):403-413

Turley CM, Lochte K, Patterson DJ (1988) A barophilic flagellate isolated from $4500 \mathrm{~m}$ in the mid-North A.tlantic. Deep Sea Res 35(7):1079-1092

Wirsen CO, Jannasch HW (1975) Activity of marine psychrophilic bacteria at elevated hydrostatic pressures and low temperatures. Mar Biol 31:201-208

Submitted: February 2, 1998; Accepted: July 7, 1998

Proofs received from author(s): September 9, 1998 